\title{
Research on CITIS' System Data Exchange Method for CALS
}

\author{
Lili Jiang and Guangxiong Hu \\ Guangdong University of Technology, Guangzhou 510006, Guandong, P.R. China \\ jiang_118888@126.com hugoon@126.com
}

\begin{abstract}
This paper studies the CITIS' (Contractor Integrated Technical Information Service)main information services and data exchange functions for CALS (Continuous Acquisition and Life-cycle Support), proposes the possibility and advantage of CITIS' data exchange with the technology of Web Service, designs and develops a CITIS' system data exchange prototype system with this technology. This System can achieve data exchange among application systems, heterogeneous operating systems and databases.
\end{abstract}

Keywords: CALS, CITIS, Web service, System data exchange

\section{INTRODUCTION}

The new concept of CALS (Continuous Acquisition and Life-cycle Support) gestates a cross-generational revolution in the enterprise systems of many countries. CITIS is established by contractor integrating the information system from the internal and external enterprise, and the CITIS provides AIU (Authorized Information User) with technical data in the contacts. The standard information services in the CITIS system is integrated from internal and external enterprise's information systems. The fact is that there is difference among operating systems platforms, development platforms, databases and the technology. So how to solve the problems of data exchange among different enterprise internal and external information systems is the important research topic of CITIS. In this paper SDEP is established as the CITIS' system data exchange platform, which satisfies the requirements of integrating enterprise internal and external information systems. The system is developed based on the CITIS' standard, XML, SOAP, and realizes the function of data exchange among prototype systems, applications and prototype database [1].

\section{THE ANALYSIS OF CITIS' USER ROLE AND THE REQUIREMENT OF DATA EXCHANGE}

CITIS' user role based on CALS contains the owner of the project, contractor, subaltern contractor, suppliers and user.

\section{A. The Owner of Project}

Please use the following format when citing this chapter:

Jiang, L., Hu, G., 2007, in IFIP International Federation for Information Processing, Volume 255, Research and Practical Issues of Enterprise Information Systems Il Volume 2, eds. L. Xu, Tjoa A., Chaudhry S. (Boston: Springer), pp. 943948. 
The owner of project is sponsors and owners of the project, who selects the contractor and signs on a contract with the contractor. He puts the related information services on the CITIS platform or gains related information services from the CITIS platform, and charge the authority of CITIS' AIU.

\section{B. The Contractor}

After selected by the project owner, the contractor will be Responsible on the whole project's development, design, test, manufacture, production and maintenance, and so on, of the whole the project. The contractors are responsible on the information services data, configuration management, information security; data index, data dictionaries, and so on, and control the data access according to the singed contract. At the same time they put the related information services on the CITIS platform or access the related information services from the CITIS platform.

\section{The Sub-Contractor}

The sub-contractors supply the contractors with about products technical information through mutual agreement. That means they access the related information services from the CITIS platform, and meanwhile put the related information services on the CITIS platform for delivery of services.

\section{The Supplier}

The suppliers supply raw materials of the products, semi-finished goods, and external cooperation processing, and so on. At the same time, they put the related information services on the CITIS platform or access the related information services from the CITIS platform as the sub-contractors do.

\section{E. The User}

The users are the end-user of the products, and can access to the standard information services of the products through CITIS platform. That means they access to the related information services from the CITIS platform.

There are core and tailorable functions in CITIS. Core functions contains acknowledge, approve or disapprove, comment, notice of delivery, receive, search, store, view; tailorable functions contains applications, archive, combine, download, edit, forward, package, query, sort, user groups, implementation planning [1].

\section{WEB SERVICE AND ITS ADVANTAGE OF SYSTEM DATA EXCHANGE}

Web Service Uses WSDL (Web Services Description Language, which used to describe the Web Service), UDDI (Universal Description, Discovery and Integration, which used to services' publishing and integration), SOAP (Simple Object Access Protocol, which used to call for services) and standard XML, it eliminates mutually exclusive problems existing in the enterprise applications and system integration, which makes it independent among the platform, development languages and publishers, makes it enabled to achieve the standard information services.[2]So Web Service is the ideal candidate to carry out CITIS' systems integration. To sum up, its technical advantages are:

Adaptability to a wide range of technology: Thanks to the current mainstream developer's support, Web Service is more compatible than other system integration 
solution. Web Service is easy to design, develop, maintenance and use. So Web Service has a wide range of technology to complete the commercial processes among application systems.

Standards and open property: Web Service based on open standards such as HTTP, SOAP, UDDI, WSDL, which are already widely accepted as the industry standard. Using Web Service can save much investment of enterprise application integration in the new technology investment.

Strong flexibility: Traditional enterprise application integration is achieved from point-to-point, so if the server is changed the client must be also changed or it will cause a system breakdown. Thanks to Web Service provides standardization interface, changed service will not affect the service call that the service server will not affect the service client's call. So Web Service contains a strong flexibility.

Low price of Integration: The traditional enterprise application integration with a high price to implementation, maintenance and upgrade their systems, but it is more suitable to complete the Web Service's implementation, maintenance and upgrade.

High dynamic: Web Service provides service requests, publishing and search function, and providing dynamic interface to implement systems integration, it is more dynamic than traditional solution which dispose enterprise application integration with static calling.

\section{ESTABLISHMENT OF SYSTEM ARCHITECTURE}

CITIS is not related to the generation of enterprise information's, however, it needs integrate internal and external enterprises system's data to CITIS' platform, and provides the data exchanges capability and information services. CITIS must consider systems heterogeneous characteristics among ERP、PDM、MES、CRM、MIS、 $\mathrm{OA}$ and so on, which are implemented in existing enterprises. Based on the above analysis the system architecture of CITIS-SDEP (System Data Exchange Platform) is established.

This system architecture contains the following characteristics:

Openness: as a data exchange platform, this CITIS-SDEP creates an information exchange platform to satisfy the systems interoperability, portability and scalability requirements, and to achieve seamless connectivity with other information systems, facing contractor's internal and external enterprises information systems' integration, and contains the conditions of expansion and upgrading.

Sharing: The hypostasis of network is that it has sharing. This CITIS-SDEP model is established based on local area network (LAN) and wide area network (Internet), data exchange standard and data transmission standard, so it makes adequate preparations of systems' openness and networking. 


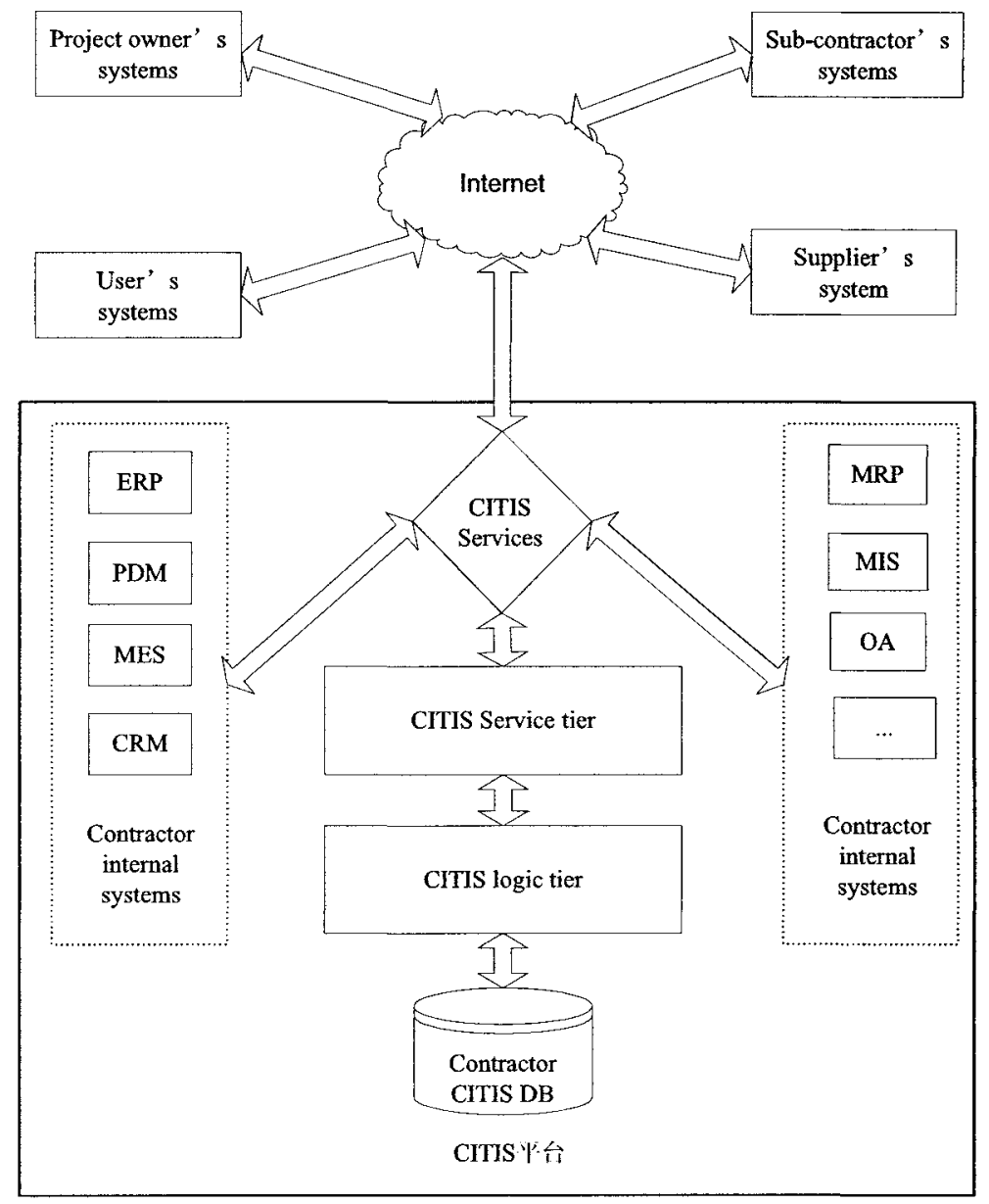

Figure 1. The SDEP's System Architecture

Standards: This model is established based on the contractor integrated information technology services GB (GB/Z 18786-2002) and standard of data format, data exchange and data transmission, which makes adequate preparations of openness and networking.

Platform: Facing the problem of system's data exchange CITIS-SDEP plays a full role of platform which do not favor any information providers or receiver and make the two sides have certain rights and obligations. 


\section{PROTOTYPE SYSTEM DEVELOPMENT OF SDEP}

CITIS - SDEP system is developed by Delphi7.0 and SQL Server 2000 database. Delphi is a visualization software development platform of Borland that has excellence of object-oriented languages and highly efficient compiler. Microsoft has developed the relational SQL Server 2000 database that has scalability from small departments to enterprise-class network [3].

CITIS - SDEP system core function is that it can integrate the enterprise internal and external enterprises information systems and provides the standard information services to the AIU with the SDEP. CITIS - SDEP has the ability of integrating the data of files from different operation systems and services platforms.



Figure 2. The System's Implementation

From the above picture, it can be found that CITIS-SDEP contains two parts. One is SDEP, which is the Web Service's core. Another part is interface in accordance with the rules of the data exchange. The information exchange processes is that interface creates SOAP massage and transfer the SOAP message to the SDEP, and provides the client systems with the information services after registering the related information in the CITIS-SDEP [4].

Following figure shows an emblematical application of system data exchange. The application situation is: Zenith is a MES (Manufacturing Execution System) system, which realizes the management of the whole products' of parts' Manufacturing information from the parts' plan step to products' or parts' procedure plan. PDM Plus is a PDM system developed by Lotsia. The two information system is independent each other. Thanks to the development requirement, PDM Plus must call for the information of products and parts in the Zenith. The whole processes are shown as following:

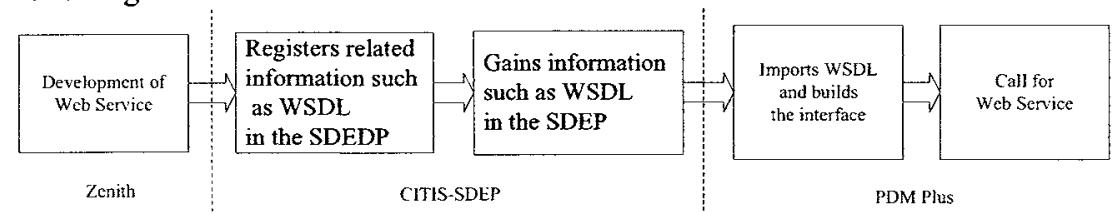

Figure 3. An Application's Implementation Processes 


\section{CONCLUSIONS}

This paper provides a prototype system design of SDEP based on Web Service, facing CITIS' system data exchange requirements. This SDEP friendly realizes the function of data exchange among heterogeneous operating systems platforms, development platforms and databases with the characteristic of the properties of open, sharing, standards and platform. It is validated that Web Service is provided with strong possibility and advantages in the CITIS' system data exchange requirements.

\section{REFERENCES}

1. People's Republic of China, CITIS (Contractor Integrated Technical Information Service) (2002).

2. Anonymous Web Service, FrontPage/Axis/Axis General (2007). http:/wiki.apache.org/ws/FrontPage/Axis/AxisGeneral

3. W. Li, Delphi6/Kylix2 SOAP/Web Service Program's Design (China Machine Press: Beijing, 2002).

4. J. Snell, D. Tidwell, and P. Kulchenko, Programming Web Services with SOAP (O'Reilly: Sebastopol, 2002). 